\title{
THE INFLUENCE OF ANTIRETROVIRAL AND ANTITUBERCULOSIS AGENTS ON THE BIOCHEMICAL AND HISTOPATHOLOGICAL INDICES OF LIVER FUNCTION IN RATS
}

\author{
O. O. Shevchuk, K. A. Posokhova, O. M. Oleshchuk, T. V. Datsko \\ I. YA. HORBACHEVSKYTERNOPIL STATE MEDICAL UNIVERSITY, TERNOPIL, UKRAINE
}

\begin{abstract}
Background. Standard antituberculosis treatment and highly active antiretroviral therapy are frequently associated with hepatotoxicity leading to drugs discontinuation.

Objective. This study aimed to assess the signs of hepatotoxicity in albino rats in case of simultaneous usage of tuberculostatics (TBS) and antiretroviral agents (ART).

Methods. Healthy rats were divided in 4 groups: $1^{\text {st }}$ control group; $2^{\text {nd }}$ group was given tuberculostatics (isoniazid - $50 \mathrm{mg} / \mathrm{kg}$, rifampicin - $50 \mathrm{mg} / \mathrm{kg}$ and pyrazinamide - $1500 \mathrm{mg} / \mathrm{kg}$ ); $3^{\text {rd }}$ group was given ART (efavirenz - $150 \mathrm{mg} / \mathrm{kg}$ and stavudine $-5 \mathrm{mg} / \mathrm{kg}$ ); $4^{\text {th }}$ group was given TBS and ART. The animals were sacrificed painlessly on the $29^{\text {th }}$ day; blood and liver samples were obtained. The main biochemical and histopathological indices were determined.

Conclusions. Comparing with control group, repeated usage of TBS caused the prominent liver injury with cytolysis and cholestasis signs, decreasing of CYP3A and CYP2E1 isozymes activity and dysfunction of protein synthesis by the liver. ART (efavirenz and stavudine) caused the elevation of transaminases activity with the increase of serum bilirubin level at the background of increase in cytochrome 450 isoforms $3 A$ and $2 E 1$ activities and total serum protein. The antiretroviral agents in case of simultaneous administration with the antituberculosis drugs diminished the hepatotoxic effects of first-line drugs for tuberculosis treatment which was confirmed by the study of liver histopathology. Such results of our experimental study give encouragement for further detailed clinical research of drug-drug interaction of both pharmacological groups due to the rising cases of HIV-associated tuberculosis in the whole world.
\end{abstract}

KEY WORDS: Isoniazid, rifampicin, pyrazinamide, efavirenz, stavudine, liver, cytochrome P450.

\section{Introduction}

The global burden of tuberculosis (TB) is enormous today (Fig. 1) [1]. The overlapping epidemiology of HIV and TB as simultaneous infections has had catastrophic consequences. The interaction between these diseases is bidirectional. HIV infection increases the risk of both primary and reactivated TB [2], and this risk increases markedly with advancing of HIV disease. The case fatality rates of HIVassociated TB are high; the estimated aggregate case fatality rate of HIV-infected TB is about $40 \%$, and may be over $50 \%$ in many developing countries [3].

When choosing therapy for patients with HIV and TB, drug-drug interactions should be carefully considered. Rifampicin is an upregulator of CYP450 enzymes that catalyzes the metabolism of a number of other drugs, including the NNRTI (Non-nucleoside reverse-transcriptase inhibitors) efavirenz (EFV).

Address for correspondence: Shevchuk OO, Medical Biochemistry Department, m. Voli, 1, Ternopil, 46001, Ukraine

Tel.: +380352-52-39-87;

E-mail: shevchukoksana777@gmail.com
Concomitant Highly Active Antiretroviral Therapy (HAART) during TB therapy is complicated by high pill burden, concerns about drug-drug interactions, paradoxical immune reconstitution reactions and the main problem is overlapping drug toxicities (table 1) $[4,5,6]$.

The treatment of tuberculosis is complicated by drug-induced hepatotoxicity, with reported rates ranging widely, from approximately 3 to $25 \%$, depending on the hepatotoxicity definitions, the regimens, the methodologies, and the study populations [7].

Hepatotoxicity is a relatively common adverse drug reaction leading to treatment interruptions in HIV patients, observed with different drug combinations [8]. Currently, the top priority for World Health Organization (WHO) is to increase coverage of ART for HIV-positive TB patients towards the $100 \%$ target [1].

Isonazid (isonicotinylhydrazine, INH) in treatment of all types of TB is associated with mild to moderate elevation of liver enzymes and sometimes with severe hepatotoxicity. Rifampicin (RFP), which is commonly used in combination with $\mathrm{INH}$, was 


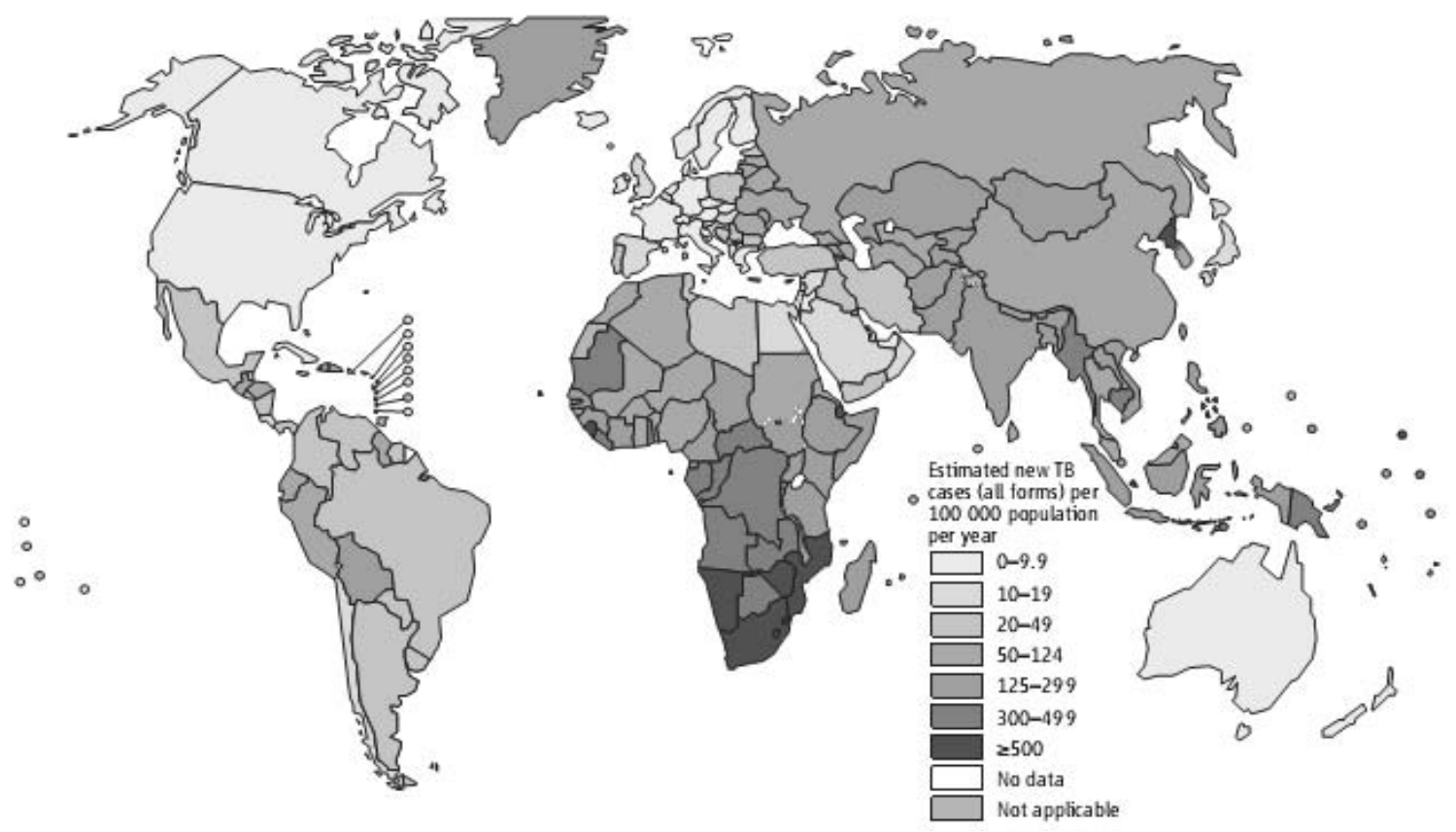

Fig. 1. Estimated TB incidence rates, 2012. Reproduced from World Health Organization. Global tuberculosis report 2013.

Table 1. Overlapping or additive adverse drugs effects of antiretroviral and first-line antituberculosis agents

\begin{tabular}{|l|l|l|}
\hline \multicolumn{1}{|c|}{ Toxicity } & \multicolumn{1}{|c|}{ Antiretroviral agents } & \multicolumn{1}{c|}{ Antituberculosis agents } \\
\hline Peripheral neuropathy & Stavudine, didanosine & Isoniazid, ethambutol \\
\hline Gastrointestinal intolerance & All & All \\
\hline Hepatotoxicity & $\begin{array}{l}\text { Nevirapine, efavirenz, all nucleoside } \\
\text { reverse transcriptase inhibitors and } \\
\text { protease inhibitors }\end{array}$ & $\begin{array}{l}\text { Isoniazid, rifampicin, } \\
\text { pyrazinamide }\end{array}$ \\
\hline Neurotoxicity (CNS) & Efavirenz & Isoniazid \\
\hline Skin rash & $\begin{array}{l}\text { Abacavir, amrenavir, nevirapine, } \\
\text { efavirenz }\end{array}$ & $\begin{array}{l}\text { Isoniazid, rifampicin, } \\
\text { pyrazinamide }\end{array}$ \\
\hline
\end{tabular}

reported to result in higher rate of liver injury, especially with the simultaneous administration of pyrazinamide (PZA). Thus in this study we investigate the influence of first-line antituberculosis and antiretroviral drugs alone and in combination on main functions of the liver.

\section{Methods}

INH, RFP and PZA were secured from "Borshchahivskiy CPP" (Ukraine). Antiretroviral agents - EFV and d4T (Aurobindo Pharma Ltd., India) were kindly provided by State Institution "Ukrainian Center forAIDSPrevention of the Ministry of Health of Ukraine".

\section{Animals and study design}

The white inbred rats $(200 \pm 20 \mathrm{~g}, \mathrm{n}=24)$ were taken from TSMU vivarium. Animals were randomly distributed into 4 groups ( $n=6)$ : 1 - intact group; 2 rats which were treated with combination of antituberculosis drugs isoniazid $(50 \mathrm{mg} / \mathrm{kg}$ ), pyrazinamide (1500 mg/kg) and rifampicin (50 mg/ $\mathrm{kg}) ; 3$ - rats which were treated with the components of HAART: efavirenz $(150 \mathrm{mg} / \mathrm{kg})$ and stavudine (d4T, $5 \mathrm{mg} / \mathrm{kg}$ ); and 4 - rats for which both antiretroviral and antituberculosis drugs in the abovementioned doses were used. A suspension of granulated tablets was introduced via the tube into the rat stomach once a day during 28 days. Rats of intact group were given equivalent quantity of distilled water. The rats were weighted and sacrificed under Ketamine hydrochloride general anesthesia on the $29^{\text {th }}$ day. The blood and liver samples were taken for investigation. All animals' procedures were performed according to the rules and requirements of European Convention for the Protection of Vertebrate Animals Used for Experimental and Other Scientific Purposes and local Ethic Committee.

Biochemical analysis

Serum activities of aspartate aminotransferase (AST) and alanine aminotransferase (ALT), alkaline phosphatase, concentration of total bilirubin, serum total protein, creatinine and urea were determined 
using standard test kits «Lachema». Thiobarbituric acid-reactive substances (TBARS), catalase activity were determined as described earlier [9, 10]. Plasma ceruloplasmin level was determined as well [11]. The liver tissue was homogenized by using the homogenizer Silent Crusher S (Heidolph, Germany). The concentrations of lipid hydroperoxides [12], TBARS, superoxide dismutase (SOD) [13], catalase activity and reduced glutathione level (G-SH) [14] were analyzed in liver homogenates. p-hydroxylase activity as a marker of CYP2E1 and N-demethylase activity as a marker for cytochrome P450 - CYP3A activity in rat hepatic microsomes were determined; liver microsomes were prepared by differential ultracentrifugation [15]. We determined the content of the active form of $\mathrm{INH}$ in serum of experimental animals also [16].

\section{Histopathological studies}

Slices of the liver (from six animals of each group) were fixed in $10 \%$ formalin, and then Lillyfixator was applied. Samples were embedded in paraffin; 5-6 $\mu \mathrm{m}$ sections were routinely stained with haematoxylin and eosin and observed using microscope LOMO Biolam.

\section{Statistical analysis}

Results were presented as the mean \pm standard error of the mean $(\mathrm{M} \pm \mathrm{m})$ and analyzed by the MannWhitney-test andANOVA-test using Statsoft STATISTICA 10 (at Systemic Statistical Analysis Department of TSMU). A probability level of less than 0.05 was considered as significant. The distribution of indices was estimated using Shapiro-Wilk normality test.

\section{Results}

Combination of the most effective and common antituberculosis agents has the most prominent negative effect on liver function. We observed the rising of liver transaminases levels and cholestatic syndrome: increasing of ALT and AST activity by 163 and $118 \%$, respectively, increasing of alkaline phosphatase and total bilirubin level - by 77 and $104 \%$, respectively, in comparison with intact control (table 2). Also, there are some problems with liver functions due to decreasing of total protein serum level by $40 \%$.

The influence of antiretroviral agent on indices of cytolysis and cholestasis was milder. We noted the increase in ALT and AST activities by 42 and $45 \%$ comparing with the control group rats (table 2 ).

The main positive findings of our study are that the concomitant administration of EFV and d4T with $\mathrm{INH}, \mathrm{RMP}$ and PZA decreased the hepatotoxicity of antituberculosis drugs (Figure 2). The group of rats which received the treatment of all five drugs had decreased levels of ALT, AST and alkaline phosphatase activity by 34,36 and $27 \%$, respectively, total bilirubin level was lower by $23 \%$, and total serum protein level was higher by $95 \%$ comparing with rats which were treated with antituberculosis agents alone. However, there was no full restoration of all indices. It was noted that the ALT, AST and alkaline phosphatase activities and total bilirubin levels were still higher in rats treated with antituberculosis agents

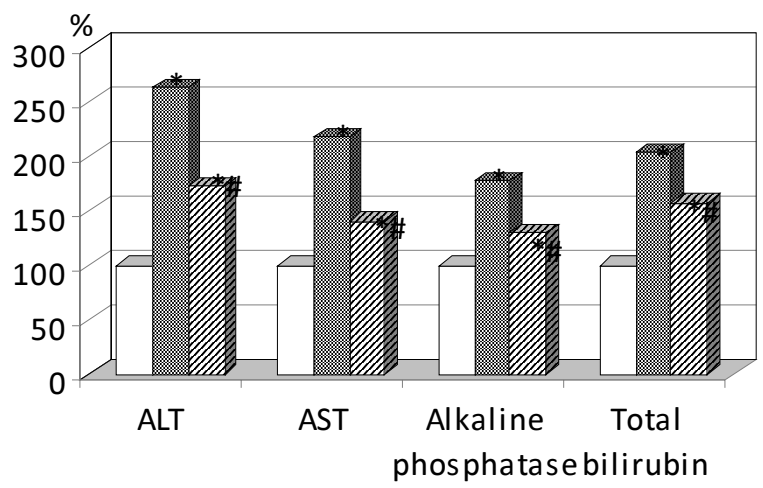

$$
\begin{aligned}
& \square \text { intact rats } \\
& \text { PZA, INH, RMP } \\
& \text { PZA, INH, RMP + EFV, d4T }
\end{aligned}
$$

Fig. 2. The cytolysis and cholestasis indices in case of antituberculosis and antiretroviral agents' administration. Notes: $\mathrm{p}<0.05$ comparatively with * - intact rats, ${ }^{*}$ - rats which were treated with combination of antituberculosis drugs isoniazid (INH, $50 \mathrm{mg} / \mathrm{kg}$ ), pyrazinamide (PZA, $1500 \mathrm{mg} / \mathrm{kg}$ ) and rifampicin (RMP, $50 \mathrm{mg} / \mathrm{kg}$ ).

Table 2. The changes of biochemical indices of serum in case of antiretroviral and antituberculosis

\begin{tabular}{|c|c|c|c|c|c|}
\hline \multirow[b]{2}{*}{$\begin{array}{l}\text { The group of } \\
\text { animals }\end{array}$} & \multicolumn{5}{|c|}{ Index } \\
\hline & $\begin{array}{c}\text { ALT, } \\
\text { mccat/l }\end{array}$ & $\begin{array}{c}\text { AST, } \\
\text { mccat/l }\end{array}$ & $\begin{array}{c}\text { Alkaline } \\
\text { phosphatase, } \\
\mathrm{mma/(I-hour)}\end{array}$ & $\begin{array}{l}\text { Total bilirubin, } \\
\mathrm{mcmol} / \mathrm{l}\end{array}$ & $\begin{array}{c}\text { Total protein, } \\
\mathrm{g} / \mathrm{l}\end{array}$ \\
\hline Control rats & $0.85 \pm 0.03$ & $1.15 \pm 0.07$ & $1.86 \pm 0.08$ & $2.38 \pm 0.10$ & $60.82 \pm 1.88$ \\
\hline INH, RFP, PZA & $2.24 \pm 0.08^{*}$ & $2.51 \pm 0.06^{*}$ & $2.38 \pm 0.17^{*}$ & $4.86 \pm 0.29^{*}$ & $36.88 \pm 0.76^{*}$ \\
\hline EFV, d4T & $1.21 \pm 0.04^{*}$ & $1.43 \pm 0.06^{*}$ & $2.07 \pm 0.04$ & $3.23 \pm 0.05^{*}$ & $74.01 \pm 0.12^{*}$ \\
\hline $\begin{array}{l}\text { INH, RFP, } \\
\text { PZA+EFV, d4T }\end{array}$ & $1.48 \pm 0.04^{\text {*\#• }}$ & $1.61 \pm 0.06^{\star \#}$ & $2.40 \pm 0.20^{\star \#}$ & $3.74 \pm 0.14^{\text {*\#• }}$ & $71.87 \pm 4.54^{*}$ \\
\hline
\end{tabular}
agents usage $(M \pm m, n=6)$

Notes. Statistical significance level is $p<0.05$ for this and for the following tables comparing with:

1. * - intact rats;

2. \# - group of rats which received antituberculosis agents INH, RFP, PZA;

3. - group of rats which received antiretroviral agents EFV, d4T. 
alone than in control rats by $73,40,29$ and $57 \%$, respectively.

The biochemical markers of intensive oxidative stress were detected after administration of combination of antituberculosis agents (Table 3). It was observed that the levels of HPL and TBARS in liver tissue increased by 86 and $144 \%$ respectively; TBARS in blood serum - by $99 \%$ in comparison with intact group on the 29th day. The decrease in SOD activity (by $39 \%$ ) and catalase activity in liver homogenates and blood serum - by $55 \%$ and $32.5 \%$, respectively, was observed. Simultaneously, the levels of G-SH and CP were lower by $29 \%$, the level of ceruloplasmin was higher by $19 \%$, respectively, compared to control group.

Antiretroviral agents caused some lipoperoxidation of cells membranes: HPL level in the liver increased by $21 \%$, TBARS in the liver tissue and serum - by 50 and $23 \%$, respectively, comparing with control rats (table 3 ). As for indices of endogenic antioxidant defense, SOD and catalase activity in the liver were lower by 46 and $40 \%$, in the serum by 31 and $32 \%$, respectively, comparing with control group. The G-SH was lower by $22 \%$, ceruloplasmin level increased by $16 \%$.

The levels of primary and secondary products of lipids membranes peroxidation were lower in the group of rats which received combination of antiretroviral and antituberculosis agents comparing with the rats which were treated with antituberculosis combination INH, RMP, PZA alone. For example, HPL level was lower by $24 \%$, TBARS in liver tissue and serum - by 32 and $30 \%$. As for activity of SOD and catalase in the liver, they were higher by 20.8 and $21 \%$, respectively.

The antiretroviral agents EFV and d4T caused the increase of $\mathrm{N}$-demethylase and $\mathrm{p}$-hydroxylase activity by 34 and $26 \%$, respectively. Similarly, antituberculosis drugs INH, RMP and PZA caused
$\mathrm{N}$-demethylase and $\mathrm{p}$-hydroxylase activity decrease by 54 and $33 \%$, respectively, all results comparing with intact rats (Figure 3 ).

The level of serum free INH was lower by $18 \%$ in rats which received combined treatment of EFV, d4T and INH, RMP, PZA, comparing with the group of animals which were treated with antituberculosis agents alone (table 4).

Histologic findings were done as described below. We observed the lobular disarray, dilation of central veins, and signs of fatty and hyaline-drops protein dystrophy in case of treatment with antituberculosis drugs. All cells had different structure and sizes. We found increased number of cells with kariopicnosis, fragmentation and karyolysis (Fig. 4 (1)). ART had no the influence on lobular structure of the liver (Fig. 4 (2)). However, we noticed the hyperplasia of hepatocytes due to the enlargement of homogenous cytoplasm and hyperplasia of granulated nuclei. Cholestasis signs were not

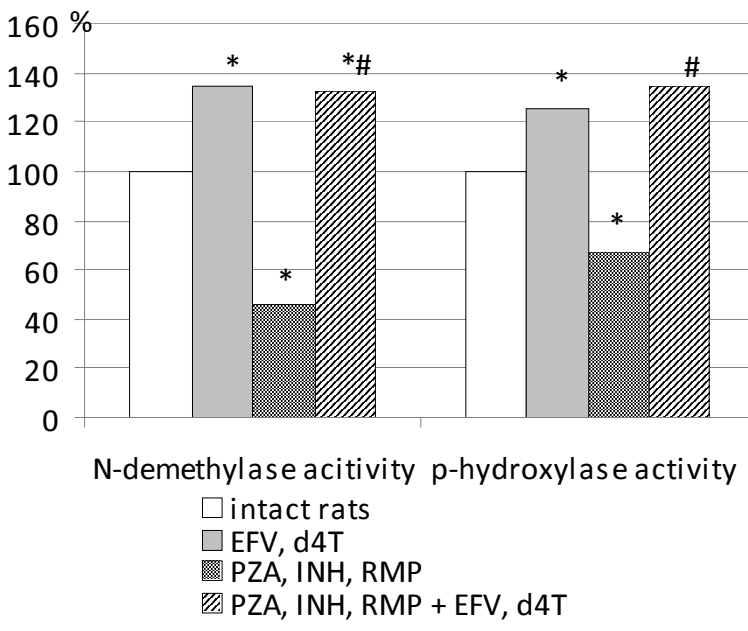

Fig. 3. The influence of ART and antituberculosis agents on $\mathrm{N}$-demethylase and $\mathrm{p}$-hydroxylase activity of liver microsomes.

Table 3. The influence of antiretroviral and antituberculosis agents on prooxidant and antioxidant homeostasis $(M \pm m, n=6)$

\begin{tabular}{|c|c|c|c|c|}
\hline \multirow[b]{2}{*}{ Index } & \multicolumn{4}{|c|}{ The group of animals } \\
\hline & Control rats & INH, RFP, PZA & EFV, d4T & $\begin{array}{c}\text { INH, RMP, } \\
\text { PZA+EFV, d4T }\end{array}$ \\
\hline $\mathrm{HPL}, \mathrm{U} / \mathrm{kg}$ & $5.1 \pm 0.26$ & $9.47 \pm 0.22^{*^{*}}$ & $6.19 \pm 0.11^{\star \#}$ & $7.20 \pm 0.21^{\star \#}$ \\
\hline TBARS (liver), $\mathrm{mcmol} / \mathrm{kg}$ & $6.73 \pm 0.23$ & $16.45 \pm 0.36^{*}$ & $10.08 \pm 0.28^{\star \#}$ & $11.22 \pm 0.61^{\star \#}$ \\
\hline TBARS (serum), mcmol/l & $0.81 \pm 0.04$ & $1.62 \pm 0.02^{*^{*}}$ & $1.01 \pm 0.03^{\star \#}$ & $1.14 \pm 0.01^{\star \# \bullet}$ \\
\hline SOD (liver), U/kg & $5.07 \pm 0.09$ & $3.09 \pm 0.09^{*}$ & $2.76 \pm 0.08$ *\# & $3.73 \pm 0.13^{\star \#}$ \\
\hline SOD (serum), U/I & $4.43 \pm 0.07$ & $3.23 \pm 0.15^{\star}$ & $3.05 \pm 0.12$ * & $3.38 \pm 0.10^{*}$ \\
\hline Catalase (liver), cat $/ \mathrm{kg}$ & $7.99 \pm 0.07$ & $3.59 \pm 0.23^{*}$ & $4.82 \pm 0.17^{\star \#}$ & $4.35 \pm 0.14^{\star \#}$ \\
\hline Catalase (serum), cat/l & $8.61 \pm 0.25$ & $5.81 \pm 0.32^{*}$ & $5.82 \pm 0.35^{\star}$ & $6.44 \pm 0.47$ \\
\hline $\mathrm{G}-\mathrm{SH}, \mathrm{mmol} / \mathrm{kg}$ & $2.37 \pm 0.04$ & $1.67 \pm 0.03^{*}$ & $1.85 \pm 0.08^{*}$ & $1.7 \pm 0.06$ \\
\hline Ceruloplasmin, $\mathrm{mg} / \mathrm{l}$ & $329.6 \pm 10.0$ & $390.8 \pm 13.5^{*}$ & $383.5 \pm 6.9$ & $371.9 \pm 10.8$ \\
\hline
\end{tabular}

Notes. In this and all the following tables: statistical significance $p<0.05$ comparatively with:

1. * - control rats;

2. \#- group of rats which received antituberculosis agents INH, RFP, PZA;

3. - group of rats which received antiretroviral agents EFV, d4T. 
Table 4. The influence of antiretroviral and antituberculosis agents on serum isoniazid level in rats $(M \pm m)$

\begin{tabular}{|c|c|c|}
\hline \multirow{2}{*}{ Indices } & \multicolumn{2}{|c|}{ Animals groups } \\
\cline { 2 - 3 } & Antituberculosis agents & $\begin{array}{c}\text { Antituberculosis } \\
+ \text { antiretroviral agents }\end{array}$ \\
\hline The content of free $\mathrm{INH}, \mathrm{mg} / \mathrm{l}$ & $11.8 \pm 0.6$ & $9.7 \pm 0.4^{*}$ \\
\hline
\end{tabular}

Notes. * - the significance level $p<0.05$ comparing with the rats which received antituberculosis drugs.

observed. In case of drug administration from both pharmacological groups, we noticed the saved lobular structure of the liver (Fig. 4 (3)). The structure of hepatic cells was normal; cytoplasm was saturated and homogeneous in all cells of the liver lobule. The histological structure of the liver was improved comparing to the liver structure of the rats which were treated with combination of antituberculosis drugs.

\section{Discussion}

At least one-third of the 34 million people living with HIV worldwide are infected with latent TB. Persons co-infected with TB and HIV are 21-34 times more likely to develop active TB disease than persons without HIV. Coinfection with HIV leads to difficulties in both the diagnosis and treatment of tuberculosis. The problem of simultaneous administration of antituberculosis and antiretroviral drugs in patients with HIV-associated tuberculosis is ambiguous due to overlapping side effect profiles of drugs both pharmacological groups, the adherence challenges of polypharmacy and their drug-drug interaction especially on the stage of metabolism by liver microsome enzymes. Today state-of-art in combination of such drugs is described below. The treatment of patients with TB and HIV should include the first line drugs for TB treatment (common combination of isoniazid, rifampicin, and pyrazinamide) and NNRTI based antiretroviral therapy regimen, if possible; efavirenz and rifampin are the preferred components [18]. It is known that EVR is metabolized by isoenzyme of CYP450 - CYP3A preferably and by CYP2B and 2A also [6]. This NNRTI causes the induction of CYP3A in the liver, but not in the intestine [19]. Nucleoside reverse-transcriptase inhibitors (NRTIs), like d4T, are metabolized by glucuronidation pathway and don't have any influence on CYP450 [20]. Concerning the antituberculosis drugs, RMP is a potent inducer of CYP3A isoenzyme, as well as of other P450 isoforms, more potent than rifapentine and rifabutin [21]. PZA can induce CYP2E1 [22]. We also know that hepatotoxicity of INH depends on activity of this isoenzyme [23].

The SAPiT trial - an open-label randomized controlled trial in Durban, SouthAfrica to determine optimal timing of ART initiation in relation to TB treatment - showed that initiation of ART during tuberculosis treatment in patients with sputum smear positive for tuberculosis and HIV-infection, reduced mortality by $56 \%$ and was associated with improved outcomes [17]. Our study reasserts the results of this trial.

We can see the improving of all liver functions due to the repeated administration of components of ART, especially total serum protein level. Such results are explained because of induction of enzymes of the liver endoplasmic reticulum by EFV [19]. The influence of antiretroviral agent on indices of cytolysis and cholestasis was mild. The increase in total bilirubin level was noted. We can explain this by the fact that one of the mechanisms of EFVinduced cholestasis is inhibition of bile acids transport [24]. Our results are supported by the clinical data of the similar studies which showed the absence of risk of isoniazid-associated hepatitis in case of concomitant HAART [25].

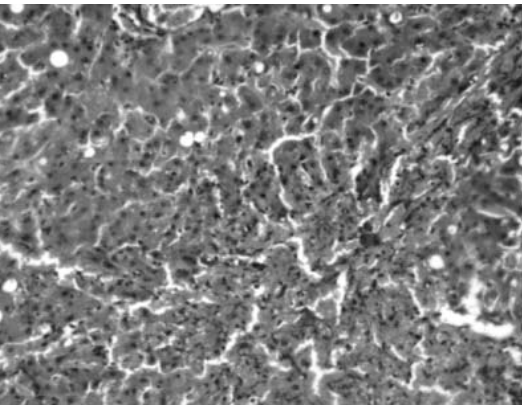

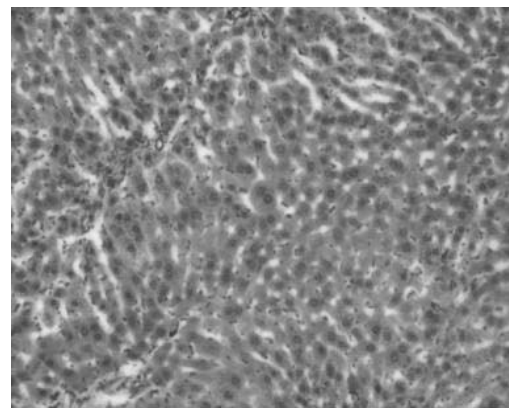

2

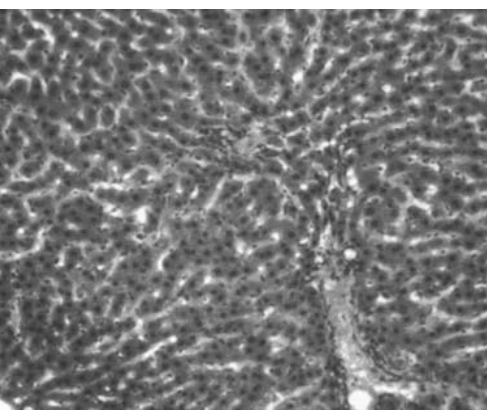

3

Fig. 4. Histopathological structure of rat liver in case of administration of antiretroviral and antituberculosis agents alone and in combination: 1. Liver structure of rats which were treated with combination of PZA, INH and RMP. Haematoxylin and eosin stain. $\times 160 ; 2$. Liver structure of rats which were treated with antiretroviral agents for 28 days. Haematoxylin and eosin stain. $\times 160$; 3 . Liver structure of rats which received combination of antituberculosis and antiretroviral agents. Haematoxylin and eosin stain. $\times 160$. 
Liver biopsy is the traditional gold standard to ascertain the degree of liver injury. Our biochemical results are confirmed by histological observations. Functionally, the liver can be divided into three zones, based upon oxygen supply. Zone 1 encircles the portal tracts where the oxygenated blood from hepatic arteries enters. Zone 3 is located around central veins, where oxygenation is poor. Zone 2 is located between the first two zones. The main mass of CYP450 enzymes is located in zone 3 of hepatic acinus [29]. Some studies showed increased activity of CYP3A and CYP2E1 in case of isoniazid and rifampicin administration [30]. That's why the decreasing of activity of these isozymes can be explained by higher hepatotoxicity of such dose of PZA which was added to the combination of INH and RMP. We can observe the necrosis of hepatic cells in centrolobular part of liver lobule which is the main cause of depression of such liver function as detoxification. We can suggest that the decrease in concentration of toxic metabolite of INH due to the combination of RMP and EVF is the key factor in decreasing of isoniazid hepatotoxicity, and the absence of cases of liver toxicity during preventive $\mathrm{INH}$ therapy with the HAART background [25, 31].

Possible mechanisms in decreasing the negative influence of antituberculosis agents in case of their combination with antiretroviral agents can be explained by the fact that inducers of cytochrome P450 enzymes stimulate synthetic and antitoxic liver functions and can decrease the quantity of necrotic hepatocytes [26]. Due to this we can see improved metabolism and detoxification processes due to the stimulation of cytochrome P450 isozymes in case of simultaneous usage of antituberculosis and antiretroviral agents. Hepatotoxicity of INH is linked to its metabolites - monoacetyl-hydrazine, hydrazine, acetyl-isoniazid and others [27]. Isoniazid is metabolized by genetically polymorphic arylamine $\mathrm{N}$ acetyltransferase type 2 (NAT2), and recent studies showed that isoniazid concentrations may be more toxic for slow acetylators after a standard therapeutic dosing [28], because of relative overdosing and higher concentration of INH toxic metabolites in the blood. That's why the increase in isonicotinyl hydrazine metabolism can accompany the mitigation of its hepatotoxic effects.

\section{Conclusion}

The present study showed that the combination of first-line antituberculosis drugs (isoniazid, rifampicin and pyrazinamide) in case of their intragastric administration during 28 days caused the prominent liver injury with cytolysis and cholestasis signs, decreasing of CYP3A and CYP2E1 isozymes activity and dysfunction of protein synthesis by the liver.

Antiretroviral agents (efavirenz and stavudine), after their administration into the stomach for 28 days, caused the elevation of transaminases activity with the increase of serum bilirubin level at the background of cytochrome 450 isoforms $3 \mathrm{~A}$ and $2 \mathrm{E} 1$ activity rising and the increase of total serum protein.

The antiretroviral agents in case of simultaneous administration with the antituberculosis drugs diminished the hepatotoxic effects of the first-line drugs for tuberculosis treatment. Such results of our experimental study may facilitate the detailed clinical research of drug-drug interaction from both pharmacological groups due to the rising cases of HIVassociated tuberculosis in the whole world.

\section{References}

1. World Health Organization. Global tuberculosis report 2014. Available at http://www.who.int/tb/publications/global_report/en/. Aceessed October 3, 2014.

2. Kwara A, Flanigan TP, Carter EJ Highly active antiretroviral therapy (HAART) in adults with tuberculosis: current status. Int J Tuberc Lung Dis 2005; 9(3): 248-257.

3. Lawn SD, Kranzer K, Wood R. Antiretroviral therapy for control of the HIV-associated tuberculosis epidemic in resource-limited settings. Clin Chest Med 2009; 30(4): 685-699.

4. Cattamanchi A, Smith R, Steingart KR et al. Interferon-gamma release assays for the diagnosis of latent tuberculosis infection in HIV-infected individuals: a systematic review and meta-analysis. J Acquir Immune Defic Syndr 2011; 56: 230-238.

5. Samandari T, Agizew TB, Nyirenda S, et al. 6month versus 36 -month isoniazid preventive treatment for tuberculosis in adults with HIV infection in Botswana: a randomised, double-blind, placebo-controlled trial. Lancet 2011; 377: 1588-1598.

6. Kwara A. Pharmacokinetics of efavirenz when coadministered with rifampin in TB/HIV co-infected patients: pharmacogenetic effect of CYP2B6 variation. J Clin Pharmacol 2008; 48(9): 1032-1040.

7. Saukkonen JJ, Powell K, Jereb JA. Monitoring for tuberculosis drug hepatotoxicity: moving from opinion to evidence. Am J Respir Crit Care Med 2012; 185(6): 598599.

8. Neuman MG, Schneider M, Nanau RM, et al. HIVantiretroviral therapy induced liver, gastrointestinal, and pancreatic injury. Int J Hepatol 2012: Article ID 760706, $1-23$.

9. Andreeva L, Kogemiakin L, Kishkun A. Modification of lipid peroxidation evaluation method according to the reaction with thiobarbituric acid. Lab delo 1988; 11: 41-43 (in Russian). 
10. Koroliuk MA, Ivanova LI, Majorova IG, et al. Method of catalase activity assessment. Lab delo 1988; 1 : 16-19 (in Russian).

11. Kamyshnikov VS. Handbook of clinical and biochemical studies and laboratory diagnosis. Moscow: MEDpress-inform; 2004: 920 (In Russian).

12. Gavrilov VB, Mishkorudnaya MI. Spectrophotometric assessment of lipid hydroperoxides quantity in blood plasma. Lab delo 1983; 3: 33-35 (in Russian).

13. Chevary S, Chaba I, Sekuy I. Role of superoxide dismutase in cellular oxidative processes and method of assessment of its biological activity. Lab delo 1985; 11 : 678-681 (in Russian).

14. Ellman GL. Tissue sulfhydryl groups. Arch. Biochem. Biophys, 1959; 82: 70-77.

15. Karuzina II, Archakov Al. The selection of microsome fraction of liver and characteristic of its oxidizing systems (in) Orechovich VN (ed) The modern methods in biochemistry. Moscow. Medicina; 1977: 4962 (in Russian).

16. Hrebennik LI. About the determination of isonicotinic acid hydrazide derivatives and their transformation products in the body. Probl tuberc 1961; 4: 69-74 (in Russian).

17. Karim SA, Naidoo K, Grobler A, et al. Timing of initiation of antiretroviral drugs during tuberculosis therapy. N Engl J Med 2010; 362: 697-706.

18. Kaplan JE, Benson C, Holmes $\mathrm{KH}$, et al. Guidelines for prevention and treatment of opportunistic infections in HIV-infected adults and adolescents: recommendations from CDC, the National Institutes of Health, and the HIV MedicineAssociation of the Infectious Diseases Society of America. MMWR Recomm Rep 2009; 58(RR-4): 1-207.

19. Berruet N, Sentenac S, Auchere D, et al. Effect of efavirenz on intestinal $p$-glycoprotein and hepatic p450 function in rats. J. Pharm. Pharmaceut. Sci 2005; 8 (2): 226-234.

20. Mouly S, Rizzo-Padoin N, Simoneau G. Effect of widely used combinations of antiretroviral therapy on liver CYP3A4 activity in HIV-infected patients. Br. J. Clin. Pharmacol. 2006; 62: 200-209.

21. Di Perri G, Marucco AD, Mondo A, et al. Drugdrug interactions and tolerance in combining antituberculosis and antiretroviral therapy Expert Opin Drug
Saf 2005; 4 (5): 821--836.

22. Kovalenko VM, Shayakhmetova AM, Bondarenko LB, et al. The influence of cytochrome P-450 2E1 on biochemical and histomorphological indices of rats liver. Suchasni problemy toksikologii. 2006;3. Available at http://www.medved.kiev.ua/arhiv_mg/st_2006/ 06_3_5.htm (in Ukrainian). Accessed October 4, 2014.

23. Yue J, Peng Ren-xiu, YANG J, et al. CYP2E1 mediated isoniazid-induced hepatotoxicity in rats. Acta Pharmacol Sin 2004 May; 25 (5): 699-704.

24. McRae MP, Lowe CM, Tian X. Ritonavir, Saquinavir, and Efavirenz, but not Nevirapine, inhibit bile acid transport in human and rat hepatocytes. JPharmacol Exp Ther 2006; 318 (3):1068-1075.

25. Tedla Z, Nyirenda S, Peeler C, et al. Isoniazidassociated hepatitis and antiretroviral drugs during tuberculosis prophylaxis in HIV-infected adults in Botswana. Am. J. Respir. Crit. Care Med. 2010. Available at http://ajrccm.atsjournals.org/cgi/reprint/20091117830Cv1. Accessed October 4, 2014.

26. Vengerovsky Al. Pharmacological approaches to regulation of liver function. Bull Sib Med 2002; 1: 2529 (in Russian).

27. De Rosa HJ, Baldan HM, Brunetti IL, Ximenes VF, Machado RG. The effect of pyrazinamide and rifampicin on isoniazid metabolism in rats. Biopharm Drug Dispos 2007; 28(6): 291-296.

28. Possuelo LG, Castelan JA, deBrito TC, et al. Association of slow $\mathrm{N}$-acetyltransferase 2 profile and antiTB drug-induced hepatotoxicity in patients from Southern Brazil. Eur J Clin Pharmacol 2008; 64: 673-681.

29. Nepomnyashchikh GI, Dyubanova GA, Nepomnyashchikh DL, et al. Universal markers of hepatotoxic influence of medical agents. Bulletin SO RAMN 2008; 6(134): 86-92 (In Russian).

30. Chen J, Raymond K. Roles of rifampicin in drugdrug interactions: underlying molecular mechanisms involving the nuclear pregnane $X$ receptor. Ann Clin Microbiol Antimicrob 2006; 5:3. Available at http:// www.ann-clinmicrob.com/content/5/1/3. Accessed October 4, 2014.

31. Huang Y-S, Chern H-D, Su W-J, et al. Cytochrome P450 2E1 genotype and the susceptibility to antituberculosis drug-induced hepatitis. Hepatology 2003; 37(4): 924-930. 